\title{
The Influence of Father-Adolescent Attachment on Adolescents' Internalizing Behavior Problems Within the Mongolian Family Context and the Analysis of Moderation Effects of Adolescents' Gender
}

\author{
Naranbulag Buyadaa ${ }^{1}$, Hana Song ${ }^{2}$ \\ Ph. D. Student, Department of Child Psychology and Education, Sungkyunkwan University, Seoul, Korea ${ }^{1}$ \\ Professor, Department of Convergence for Social Innovation/Child Psychology and Education, \\ Sungkyunkwan University, Seoul, Korea ${ }^{2}$ \\ 몽골 청소년과 아버지와의 애착이 청소년의 내현적 문제행동에 미치는 영향: \\ 청소년 성의 조절효과 분석 \\ 나란볼락 ${ }^{1}$ 송하나 ${ }^{2}$ \\ 성균관대학교 아동청소년학과 박사과정생마엉균관대학교 소셜이노베이션융합/아동청소년학과 교수 ${ }^{2}$
}

Objectives: The purpose of this study was to examine the influence of father-adolescent attachment on adolescents' internalizing behavior problems within the Mongolian family context. Additionally, the moderation effect of adolescents' gender was also examined.

Methods: One hundred seventy four Mongolian adolescents who lived in Ulaanbaatar, Mongolia participated in this study. The participants was 13 to 15 years old, and 69 out of 174 participants were boys. Consent was taken from participants and their parents. Instructions, consent forms, and questionnaires written in English were translated into Mongolian language. Participants responded to questionnaires that measured attachment to fathers, adolescents' depression, and anxiety. Data were analyzed using hierarchical multiple regression.

Results: Results of this study showed that there was a significant difference between sons and daughters in the attachment to their fathers. Attachment security between sons and fathers was higher than that between daughters and fathers. Gender differences were also found in adolescents' depression and anxiety. Levels of depression and anxiety in girls were significantly higher than in boys. In addition, attachment to fathers negatively predicted adolescents' internalizing behavior problems including depression and anxiety. In particular, the moderation effect of adolescents' gender was also significant. Specificially, girls' attachment to fathers negatively predicted girls' internalizing behavior problems, but no significant finding was reported in the relationship between fathers and boys.

Conclusion: Findings suggested a protective role of adolescents' attachment to fathers against adolescents' internalizing behavior problems, and were discussed in terms of characteristics of parent-child relationship in Mongolian culture. The role of attachment on adolescents' mental health was suggested.

Keywords: Mongolian culture, attachment, father, internalizing behavior problem, adolescent

Corresponding Author: Hana Song, Professor, Department of Convergence for Social Innovation/Child Psychology and Education, Sungkyunkwan University, 25-2, Sungkyunkwan-ro, Jongno-gu, Seoul, Korea E-mail: jni4ever@skku.edu
(c)The Korean Association of Child Studies

This is an Open Access article distributed under the terms of the Creative Commons Attribution Non-Commercial License (http:// creativecommons.org/licenses/by-nc/4.0) which permits unrestricted noncommercial use, distribution, and reproduction in any medium, provided the original work is properly cited. 


\section{Introduction}

최근 몽골에서는 빠른 산업화와 도시화에 따른 가족 해체와 세대 갈등의 문제가 심화되면서 청소년 정신건강에 대한 관심 이 늘어나고 있다. 2018년 몽골의 국가보고서에 따르면 도시 에 거주하는 청소년의 삼분의 일 이상이 우울 및 정서 문제를 경험한 것으로 나타났으며(Khulan \& Nominerdene, 2018), 또 한 자살 사례의 $29.4 \%$ 가 10 대에서 20 대 청소년인 것으로 나 타났다(Unurmaa, 2017). 이처럼 몽골 청소년의 정신건강은 사 회적으로 큰 이슈가 되고 있으나 실제 몽골 청소년을 대상으 로 한 연구는 아직까지 거의 없는 실정이다.

아동들은 청소년기로 접어들면서 신체적, 심리적 변화로 인한 정서적 혼란을 경험할 수 있고 정체감 형성 과정에서의 불안정성, 학업스트레스, 부적응적 대인 관계 등으로 인해 다 른 발달 시기보다 높은 불안을 경험한다고 알려져 있다(Rice $\&$ Dolgin, 2005). 청소년 정신건강을 다룬 선행 연구들(Kang, 2013; Thapar, Collishaw, Pine, \& Thapar, 2012)은 가족의 영향 중에서도 부모자녀 관계를 우울이나 불안과 같은 내현적 문제 행동의 결정적인 위험 요인으로 보고 있다. 특히, 부모와의 애 착은 생의 초기에 형성되어 자기 자신과 타인에 대한 정신적 표상을 형성하고 청소년기의 정신건강에 영향을 미친다. 즉, 한 개인이 심리적 고통, 위협, 실패의 위험을 경험할 때 애착관 계에 대한 내적 표상의 활성화가 정서조절과 스트레스 대응의 기반이 된다(Greenberg, 1999).

부모와의 애착과 청소년 정신건강에 대한 선행 연구들을 살펴보면 부모와 불안정 애착관계에 있다고 보고한 청소년 들이 안정 애착관계에 있는 청소년들보다 더 높은 우울을 보 고하였다(Kamkar, Doyle, \& Markiewicz, 2012). 불안정 애착 의 하위 요인 중 심한 우울을 호소한 청소년들은 부모와 회 피애착을 형성한 경우가 많았으며(Rawatlal, Kliewer, \& Pillay, 2015), 집착하는 양가적 유형의 애착을 형성한 청소년들 역시 높은 수준의 불안과 우울을 보이는 것으로 나타났다(Chorot, Valiente, Magaz, Santed, \& Sandin, 2017). 또한 부모와의 애착 은 종단적인 영향을 미치는 것으로 보고되었는데 부모와 불 안정 애착을 형성한 아동들이 이후 청소년기에 더 높은 우울 을 보이는 것으로 나타났다(Breinholst, Esbjørn, \& ReinholdtDunne, 2015). 그러나 청소년의 정신건강에 대한 부모와의 애 착의 영향이 몽골 문화에서도 유사하게 나타나는지 확인된 바 가 없으므로 본 연구에서 이를 검증해보려 하였다.

몽골의 부모와 청소년 자녀와의 관계를 살펴보면, 살아갈 수 있는 방법을 알도록 양육하는 것이 부모의 큰 역할이다. 부
모는 사계절에 적응하면서 가축 키우기, 사냥하기, 이동하기 등 전통적 삶의 방식을 알려주고 자연을 이해하기, 책 읽기, 부모와 어른을 존중하기 등을 중요하게 생각하며 양육한다 (Enkhtuya, 2016). 독자적으로 살아갈 수 있는 능력이 강조되 기 때문에 아주 어린 유아기부터 작은 물건을 들고 옮기기 등 나이에 맞는 일을 하면서 책임을 배우도록 한다.

여러 동양 문화권의 전통 사회에서는 어머니가 자녀의 양육 을 주로 담당하고 아버지가 직접 자녀와 상호작용하는 일은 드 문 것으로 알려졌다. 몽골은 전통적으로 확대가족 형태가 일 반적인 유목민 문화를 가지고 있다. 유목민 사회는 남성중심의 가부장적 체계를 가지고 있지만 여성이 가정경제를 꾸려가거 나 자녀를 양육하는데 중심적인 역할을 하는 모계중심의 특성 도 가지고 있다(Rossabi, 2021). 몽골에서도 어린 자녀의 양육이 나 교육은 어머니와 집안의 여성들이 주로 담당한다. 몽골 아버 지들은 가족의 일에 크게 관여하지는 않는 편이다. 하지만 아동 후기부터는 아버지의 역할이 중요해지는데 자녀에게 유목민으 로 살아가는 생활방법을 알려주어야 하기 때문이다(Enkhtuya, 2016). 따라서 몽골에서 청소년기는 아버지의 영향이 더 커지는 시기라고 할 수 있다. 특히 몽골 남자들은 독립적인 역할을 하 는 성인이 될 때까지 아버지와 직접 상호작용하는 경우가 많다.

현대 사회에서 아버지가 자녀에게 유목민의 생활을 직 접 교육하는 전통적 방식이 크게 변화되었다. 하지만 아버지 는 자녀에게 여전히 중요한 존재로서 특히 아버지의 체벌이 나 강압적 훈육, 무관심 등이 청소년의 정신건강에 영향을 미 친다는 것이 주목되고 있다. 몽골의 한 국립보고서에 따르면 아버지와 부정적 관계를 형성한 청소년들의 절반 이상이 높 은 수준의 불안을 보인 것으로 나타났다(Tumennast, Bumdari, Batbaatar, \& Erkhes, 2019). 또한 자녀의 건강한 발달을 위해 서 가정의 경제적인 지원보다 아버지의 양육 참여가 중요하 다는 점이 지적되었다(Oyun-Erdene, Ichinkhorloo, Jagalsikhan, \& Bulganzaya, 2018). 그러나 뉴스나 정책보고서가 이러한 방 향을 언급하였을 뿐 몽골 아버지와 청소년 자녀의 애착을 포 함한 정서적 상호작용에 대해서는 거의 알려진 바가 없다. 따 라서 본 연구에서는 몽골 청소년의 내현적 문제행동에 영향을 주는 아버지와의 애착에 초점을 맞추려 하였다.

일반적으로 애착 대상으로서의 아버지의 역할은 어머니와 비교해서 보다 간접적이거나 이차적인 것으로 언급되어 왔다 (Freeman, Newland, \& Coyl, 2010; Lamb \& Lewis, 2013). 영유 아의 양육을 담당하는 주양육자가 대부분의 문화권에서 어머 니이고 남성보다는 여성이 자녀와의 정서적 상호작용을 더 많 이 한다고 알려져 있기 때문이다. 하지만 자녀들은 성장하면 
서 여러 사람과 상호작용하는 가운데 다중적인 애착을 형성하 게 되는데(Colin, 1996), 아버지와의 애착관계에 대한 내적 표 상 역시 영아기에서 청소년기까지 지속적으로 형성된다.

청소년의 정신건강에 대한 아버지 애착의 영향은 여러 문 화권에서 검증되어 왔다. 아버지와 안정 애착을 형성한 청 소년들은 우울과 불안을 포함한 내적 문제행동을 적게 보였 으며(Agerup, Lydersen, Wallander, \& Sund, 2015), 아버지와 의 불안정 애착은 청소년의 우울과 내현적 문제행동에 유의 한 영향을 미치는 것으로 나타났다(Duchesne \& Ratelle, 2014; Grossmann et al., 2002; Pan, Zhang, Liu, Ran, \& Teng, 2016). 그 외에 아버지와 자녀 사이의 상호작용의 질은 어머니보다 청소 년의 학교적응과 사회능력 및 우울 등의 문제행동을 더 잘 예 측하는 것으로 나타났다(Lei \& Wu, 2007; Lieberman, Doyle, \& Markiewicz, 1999). 또한 종단 연구에서 아동기에 형성된 어머 니, 아버지와의 불안정 애착은 아동기 우울과 그 이후 청소년 기 우울까지 영향을 미치는 것으로 나타났다(Breinholst et al., 2015). 이처럼 아버지와의 애착은 어머니와는 별개로 청소년 들의 사회적 기능 및 문제행동을 유의하게 예측하였다.

몽골 청소년과 아버지와의 애착에 대한 연구는 거의 없 으나 아버지와 청소년 자녀와의 관계를 포괄적으로 살펴보 면, Ochir (2017)은 학령기 아동 70\%가 자신이 되고 싶은 롤 모델로 아버지를 꼽았다고 하였으며, Mongolian National Broadcasting (MNB, 2013)에서 몽골 아동과 청소년들은 자신 감을 심어준 사람으로 어머니보다 아버지를 더 많이 언급한 것으로 나타났다. 앞서 언급한 대로 몽골에서 아동기 이후 청 소년기까지 아버지의 역할이 커진다는 점을 고려한다면 아버 지와의 긍정적인 애착관계가 몽골 청소년의 내현적 문제행동 을 감소시키는데 영향을 미칠 것으로 생각된다.

한편 몽골 문화의 특성상 아버지-자녀 관계는 자녀의 성에 따라 차이가 있을 것으로 예측된다. 몽골의 유목민 문화에서 는 여자와 남자가 담당하는 일에 차이가 있다. 말린 소똥 모으 기와 우유로 발효제품 만들기는 여자아이들이, 양과 염소 몰 기와 말타기는 주로 남자아이들이 담당한다(Enkhtuya, 2016). 특히 아버지는 아들이 외부세계를 탐색하고 살아가는데 필요 한 다양한 기술을 습득할 수 있도록 도우며 아들과 정서적 상 호작용을 자주 한다. 따라서 몽골의 아버지-아들의 관계는 아 버지-딸보다 상대적으로 가깝다고 볼 수 있다. 그러나 산업화 된 몽골 사회에서 가계를 물려받는 아들보다 독립적으로 살아 가야 하는 딸을 더 많이 교육시키는 경향이 있고, 여성의 사회 진출 지원이 늘어났다(Jung, 2008). 즉 부모가 아들과 딸을 차 별 없이 교육해야 한다는 인식이 증가하는 추세이다. 이와 함
께 예전에 비해 아버지가 자녀 양육에 참여하는 일이 늘어났 다(MNB, 2013). 그러나 애착의 주체로서 몽골 아버지의 역할 에 대해서는 아직 검증된 바가 없는 실정이다.

다른 나라의 선행연구들에서 부모와의 애착이 우울이나 불안에 미치는 영향이 청소년의 성에 따라 차이가 있다는 것 이 제시되었다. 그러나 우울이나 불안이 여성에게서 더 많이 나타난다(McGuinness, Dyer, \& Wade, 2012)고 알려져 있음에 도 불구하고 애착의 영향에 대한 성차는 일관성 있게 보고되 지 않았다. Cooper, Shaver와 Collins (1998)의 연구에서는 부모 와의 불안정 애착이 여자청소년의 우울에 유의한 영향을 주는 것으로 나타났지만, Pan 등(2016)은 어머니와의 애착을 통제 했을 때 아버지와의 불안정 애착관계가 여학생보다 남학생의 우울에 강한 영향을 미친다고 하였다.

몽골 문화에서 부모와 자녀 사이의 친밀성을 고려한다면 아 버지와 상호작용을 많이 하는 아들이 아버지와의 애착 관계에 따라 문제 행동에 더 크게 영향을 받을 수 있을 것이다. 반면 여 자청소년이 우울이나 불안에 취약할 수 있다는 점을 고려한다 면, 아버지와의 애착관계에 따라 문제행동이 더 민감하게 변할 가능성이 있다. 그러나 실제로 검증된 바가 없기 때문에 본 연 구에서는 몽골 아버지가 아들과 딸에게 미치는 영향에 어떠한 차이가 있는지, 내현적 문제행동에 대한 청소년 성의 조절효과 를 알아보았다. 본 연구의 연구 문제는 다음과 같다.

\section{연구문제 1}

몽골 청소년과 아버지와의 애착관계, 몽골 청소년의 내현적 문제행동(우울과 불안)은 청소년의 성에 따라 차이가 있는가?

\section{연구문제 2}

몽골 청소년과 아버지와의 애착관계는 몽골 청소년의 내현적 문제행동(우울과 불안)에 어떠한 영향을 미치는가?

\section{연구문제 3}

몽골 청소년과 아버지와의 애착관계가 몽골 청소년의 내현적 문제행동에 미치는 영향은 청소년의 성에 따라 차이가 있는가?

3-1. 몽골 청소년과 아버지와의 애착관계가 청소년의 우울 에 미치는 영향은 성에 따라 차이가 있는가?

3-2. 몽골 청소년과 아버지와의 애착관계가 청소년의 불안 에 미치는 영향은 성에 따라 차이가 있는가? 


\section{Methods}

\section{연구대상}

본 연구를 위해 몽골의 수도인 울란바토르에 소재한 4 개의 종 합학교에서 만 13-15세 몽골 청소년 200명을 표집하였다. 몽 골의 교육체계는 유치원과 종합학교로 나누어지며 12년제 로 구성되어 있다. 본 연구에서는 불안이 증가하는 초기 청소 년기를 대상으로 하였는데 종합학교의 1-5학년은 한국의 초 등학교, 6학년부터는 중학교와 같다. 몽골 청소년 중 12 세에 서 15,16 세 까지의 연령이 한국의 중학교 청소년에 해당한다. 이러한 점을 고려하여 한국의 중학교 $1,2,3$ 학년과 동일한 연 령을 연구대상으로 정하였다. 연구에 참여한 200 명의 청소년 중 아버지와 거주하지 않는 한부모 가정의 청소년 26 명을 제 외한 174 명의 자료가 최종적으로 분석되었다. 전체 연구대상 의 평균 연령은 만 13.3 세 $(S D=.90)$ 였으며 13세는 106명, 14-5 세는 68명이었다. 또한, 남학생 69명(39.7\%), 여학생 105명 $(60.3 \%)$ 이었고 아버지의 연령대는 40 대였다.

\section{연구도구}

\section{청소년-아버지 애착관계}

청소년과 아버지와의 애착관계를 측정하기 위해 Armsden과 Greenberg (1987)가 개발하고 Wilkinson과 Goh (2014)가 short form으로 재구성한 Inventory of Parent and Peer Attachment-45 를 사용하였다. 이 척도는 신뢰, 의사소통, 소외 등 3 개 하위요 인에 어머니, 아버지, 또래와의 애착을 각각 측정하는 15 개씩 의 문항으로 구성되어 있다. 신뢰는 부모에 대한 믿음과 수용, 의사소통은 부모-자녀 간의 친밀한 대화, 그리고 소외는 부모 의 무관심과 이해 부족을 의미한다. 이 중 아버지와의 애착을 측정하는 15 문항을 본 연구에 사용하였다. 영어로 된 원 도구 를 이중 언어를 사용하는 전문가가 몽골어로 번역한 뒤 다시 역번역하는 과정을 거쳤고 연구자와 몽골의 언어 학자가 안면 타당도를 살피면서 문항을 수정하였다. 또한 확인적 요인 분 석을 거쳐 도구의 구성타당도를 확인하였다 $\left(\chi^{2}=124.13, p<\right.$ $.001, \mathrm{CFI}=.96, \mathrm{RSMEA}=.06$ ).

애착의 하위 요인 중 신뢰는 "아버지는 나를 있는 그대로 받아들여 주신다(Аавын ҮҮргээ сайн биелҮҮлж байгааг би мэдәрдэг).", 의사소통은 “아버지는 나의 어려움을 이야기 하도록 격려해 주신다(Өөрт тулгарсан аливаа асуудал, саад бэрхшээлийн талаар ярихад минь аав тусалдаг).”, 또한 소외 는 "부모님은 내가 요즘 어떤 일을 겪고 있는지 이해하지 못하 신다(СүҮлийн үед би ямар асуудал, бэрхшээл дунд байгааг аав минь ойлгохгүй байгаa).”와 같은 문항을 포함하고 있다. 아버지와의 애착관계를 청소년들이 보고하였는데, 청소년들 은 각 문항을 읽고 아버지와의 관계에 대해 전혀 그렇지 않다 (1점)에서 항상 그렇다(5점)의 리커트척도로 응답하였다. 전 체 문항의 총점을 합산하였고 점수가 높을수록 아버지와 긍정 적이고 안정적인 애착 관계가 형성된 것을 의미한다. 본 연구 에서 신뢰도를 분석한 결과 Cronbach's $\alpha$ 가 신뢰에서 .89 , 의사 소통에서 .92 , 소외에서, .67 , 전체에서 .77이었다.

\section{청소년의 내현적 문제행동}

청소년의 우울과 불안을 포함하는 내현적 문제행동을 측정하 기 위해 Achenbach과 Rescorla (2011)가 개발한 Youth Self-Report를 사용하였다. 이 도구의 하위요인 중에서 우울과 불안 에 해당하는 8 문항씩 총 16 개 문항을 사용하였다. 우울은 슬 픔, 공허함, 무가치, 불면 등 정서, 인지, 신체적 증상을 경험하 는 상태이며, 불안은 일어나지 않은 일에 대한 과잉각성과 결 과의 예측에 대한 초조, 긴장을 경험하는 정서적 상태를 말한 다. 이 도구 역시 영어로 된 원 도구를 이중언어 전문가가 몽골 어로 번역하고 이를 다시 역번역하여 수정하였고 연구자와 몽 골의 언어학자가 안면 타당도를 확인하였다. 다음으로 확인적 요인분석을 실시하여 우울과 불안으로 된 2 요인 구조를 확인 하였다 $\left(\chi^{2}=193.99, p<.001, \mathrm{CFI}=.91, \mathrm{RSMEA}=.07\right)$. 청소년 들은 각 문항을 읽고 전혀 그렇지 않다(0점)에서 매우 그렇다 (2점)까지 리커트척도로 응답하였다. 각 하위요인별로 문항의 총점을 합하였고 점수가 높을수록 우울과 불안이 높은 것을 의미한다. 내현화 문제행동 척도의 신뢰도는 Cronbach's $\alpha$ 가 우울에서 .89, 불안에서 .73, 전체 .81이었다.

\section{연구절차와 자료분석}

몽골의 청소년을 표집하기 위해 몽골의 수도 울란바토르에 위 치한 4 개 종합학교의 교장과 교사에게 본 연구에 대해 설명하 고 허락을 구한 뒤 동의서에 서명을 받았다. 담임 교사를 통해 연구에 참여할 학생을 모집하는 동안 피험자 모집과정에서 몽 골은 물론 전 세계가 COVID-19로 인해 직접적인 대면이 불 가능한 상황이 지속되었다. 이에 연구자가 직접 설문을 실시 하는 방식 대신 담임교사의 도움을 얻어 참여학생들이 접속할 
Table 1

Mean, SD, Differences by Gender of Research Variables

\begin{tabular}{|c|c|c|c|c|}
\hline Variables & & $M(S D)$ & $t$ & $p$ \\
\hline & Girls & $47.70(10.18)$ & \multirow{2}{*}{$\begin{array}{l}2.78^{* *} \\
2.78^{* *}\end{array}$} & \multirow{2}{*}{$\begin{array}{l}.006 \\
.006\end{array}$} \\
\hline & Total & 49.38 ( 9.98) & & \\
\hline \multicolumn{5}{|c|}{ Adolescents' internalizing behavior problems } \\
\hline & Total & $2.51(3.39)$ & $\begin{array}{l}-5.16^{* * *} \\
-5.16^{* * *}\end{array}$ & $\begin{array}{l}.000 \\
.000\end{array}$ \\
\hline \multirow[t]{2}{*}{ Anxiety } & Boys & $4.13(2.22)$ & \multirow{2}{*}{$\begin{array}{l}-3.99^{* * *} \\
-3.99^{* * *}\end{array}$} & \multirow{2}{*}{$\begin{array}{l}.000 \\
.000\end{array}$} \\
\hline & Girls & $5.87(3.13)$ & & \\
\hline
\end{tabular}

Note. $N=174$.

${ }^{* *} p<.01 .{ }^{* * *} p<.001$.

수 있는 학교 홈페이지를 통해 링크를 공유하고 온라인으로 설문지를 실시하는 방식을 취하였다. 참여를 원하는 학생들과 그 부모들에게 연구에 대해 설명하고 모두 동의서에 서명하도 록 하였다.

연구 도구들은 몽골어로 번역과 역번역을 한 뒤 안면타당 도를 살펴 수정하였고 예비실험을 통해 청소년들의 문장이해 에 문제가 없는지 확인하였다. 구글 드라이브로 인구학적 변 인에 대한 문항과 도구의 최종 문항들을 작성하여 로딩하였고 답변은 구글 드라이브에 자동저장되도록 설정하였다. 정보의 보안을 유지하기 위해 참여자 이름은 닉네임과 코드로 대치하 였다. 학생들이 설문을 실시하는 데는 약 15 분 내외가 소요되 었다. 참여 학생들에게는 감사의 의미로 모바일 데이터 요금 쿠폰을 지급하였다.

자료분석은 먼저 연구도구의 타당도와 신뢰도를 알아보기 위해 확인적 요인분석을 실시하고 Cronbach's $\alpha$ 를 구하였다. 기술치 분석을 위해 평균과 표준편차를 구하였고 Pearson 적률 상관분석을 실시하였다. 다음으로 연구문제 1 의 분석을 위해 $t$-test를 실시하였고 연구문제 2 와 연구문제 3 을 분석하기 위 해 우울과 불안을 준거변인으로 한 위계적 회귀분석을 실시하 였다. Baron과 Kenny (1986)의 제안에 따라 조절효과를 상호작 용으로 검증하는 단계적인 방식을 취하였다. 위계적 회귀분석 에서 맨 처음 예측치인 아버지 애착의 영향력을 알아보고, 다 음 단계에서 조절변인인 성의 영향력을 알아보고 마지막으로 애착과 성의 상호작용의 영향을 검증하였다. 상호작용이 유의 한 경우에는 성의 조절효과가 유의한 것으로 볼 수 있으며 아
노바모델의 단순주효과 검증과 같이 조절효과의 유형을 검증 하였다(Baron \& Kenny, 1986; Robinson, Tomek, \& Schumacker, 2013). 본 연구에서는 성이 유목변인이므로 남자와 여자청소 년 집단 각각에서 애착이 준거변인에 미치는 영향을 단순회 귀분석으로 알아보았다. 자료분석에는 PASW 18.0 (SPSS Inc., Chicago, IL)과 AMOS 18.0 (IBM Co., Armonk, NY) 프로그램 을 사용하였다.

\section{Results}

\section{기술치 분석 및 상관 분석}

본 연구의 연구문제 분석에 앞서 전체 변인들의 분포와 정규 성을 확인하기 위해 왜도 및 첨도를 살펴보았다. 그 결과 왜도 의 절대값이 3 미만, 첨도의 절대값이 10 미만에 해당하여 연구 변인들이 모두 정규성을 충족하는 것으로 나타났다. 다음으 로 각 변인의 평균과 표준편차가 Table 1 에 제시되어 있다. 그 리고 상관 분석을 실시한 결과가 Table 2에 나타나 있다. 주요 한 결과를 살펴보면 청소년-아버지 애착은 청소년의 우울 $(r=$ $-.58, p<.001)$ 과 유의한 부적 상관이 있었고, 불안 $(r=-.45, p<$ .001)과도 부적 상관이 유의한 것으로 나타났다. 또한 조절변 인인 청소년의 성과 우울 $(r=.37, p<.001)$ 및 불안 $(r=.29, p<$ .001)과의 상관도 유의하였다. 
Table 2

Correlations Between Variables

\begin{tabular}{lccc}
\hline & 1 & 2 \\
\hline 1. Adolescents' gender & - & & 3 \\
2. Father-adolescent attachment & $-.21^{* *}$ & - & $-.58^{* * *}$ \\
3. Adolescents' depression & $.37^{* * *}$ & $-.45^{* * *}$ & - \\
4. Adolescents' anxiety & $.29^{* * *}$ & $70^{* * *}$ \\
\hline
\end{tabular}

Note. $N=176$.

${ }^{* *} p<.01 .{ }^{* * *} p<.001$.

Table 3

The Influence of Father-Adolescent Attachment on Adolescents' Depression and Moderation Effects of Adolescents' Gender

\begin{tabular}{|c|c|c|c|c|c|c|c|}
\hline & & \multicolumn{2}{|c|}{ Model 1} & \multicolumn{2}{|c|}{ Model 2} & \multicolumn{2}{|c|}{ Model 3} \\
\hline \multicolumn{2}{|r|}{ Variables } & $\beta$ & $t$ & $\beta$ & $t$ & $\beta$ & $t$ \\
\hline \multirow[t]{4}{*}{ Depression } & Father-adolescent attachment (A) & -.39 & $-5.50^{* * *}$ & -.32 & $-4.74^{* * *}$ & .39 & 1.62 \\
\hline & $A \times B$ & & & & & -1.18 & $-3.08^{* *}$ \\
\hline & $R^{2}$ & \multicolumn{2}{|c|}{.15} & \multicolumn{2}{|c|}{.23} & \multicolumn{2}{|c|}{.27} \\
\hline & $p$ value & \multicolumn{2}{|c|}{.000} & \multicolumn{2}{|c|}{.000} & \multicolumn{2}{|c|}{.002} \\
\hline
\end{tabular}

Note. $N=174$.

${ }^{* *} p<.01 .{ }^{* * *} p<.001$.

\section{연구문제 분석}

연구문제 1: 아버지와의 애착과 내현적 문제행 동에서의 성차

연구문제 1 은 아버지와의 애착과 내현적 문제행동에서의 성 차를 검증하는 것으로 위의 Table 1 에 $t$-test 분석 결과가 나타 나 있다. 남학생이 여학생보다 아버지와 안정적인 애착 관계 를 형성한 것으로 나타났다 $(t=2.78, p<.01)$. 또한 내현적 문 제행동에 대해서는 여학생이 남학생보다 우울 $(t=-5.16, p<$ $.001)$ 및 불안 $(t=-3.99, p<.001)$ 모두 유의하게 높은 것으로 나타났다.

연구문제 2와 연구문제 3: 아버지와의 애착이 몽골 청소년의 우울과 불안에 미치는 영향과 성 의 조절효과

연구문제 2 와 연구문제 3 은 아버지와의 애착관계가 청소년의 내현적 문제행동에 미치는 영향 및 성의 조절효과를 검증하는 것으로 우울과 불안을 종속변인으로 한 위계적 회귀분석으로
한꺼번에 분석할 수 있으며 그 결과가 Table 3과 Table 4에 제시 되어 있다. 앞서 분석방법에서 언급한 바와 같이 아버지와의 애착(예측변인), 청소년의 성(조절변인), 아버지와의 애착과 청소년 성 간의 상호작용항을 위계적 회귀모델에 투입하여 주 효과와 상호작용효과를 알아보았다.

우선 우울에 대한 결과가 Table 3에 나타나 있다. 1단계에서 아버지의 애착은 청소년의 우울 $(\beta=-.39, p<.001)$ 에 유의한 부적 영향을 미치는 것으로 나타났다. 이는 아버지와의 애착 안정성이 높을수록 청소년의 우울 수준이 낮다는 것을 보여준 다. 다음으로 2 단계에서 청소년의 성의 영향이 정적으로 유의 한 것으로 나타났다 $(\beta=.30, p<.001)$. 이는 여학생이 남학생 보다 우울이 더 높다는 것을 제시한다. 마지막으로 3 단계에서 청소년 성의 조절효과를 알아보기 위해 청소년-아버지 애착 과 청소년 성의 상호작용항이 투입되었다. 상호작용이 투입된 후 아버지 애착의 주효과는 더 이상 유의하지 않았으나 청소 년 성과의 상호작용효과가 유의한 것으로 나타났다 $(\beta=-1.18$, $p$ <.01). 우울을 종속변인으로 한 전체 회귀모델은 유의하였 으며 $(F=21.53, p<.01)$ 변량의 약 $27 \%$ 를 설명하였다.

Table 3에서 상호작용이 유의하였으므로 청소년 성의 조절 효과를 상세히 알아보기 위해 남자청소년과 여자청소년 집단 


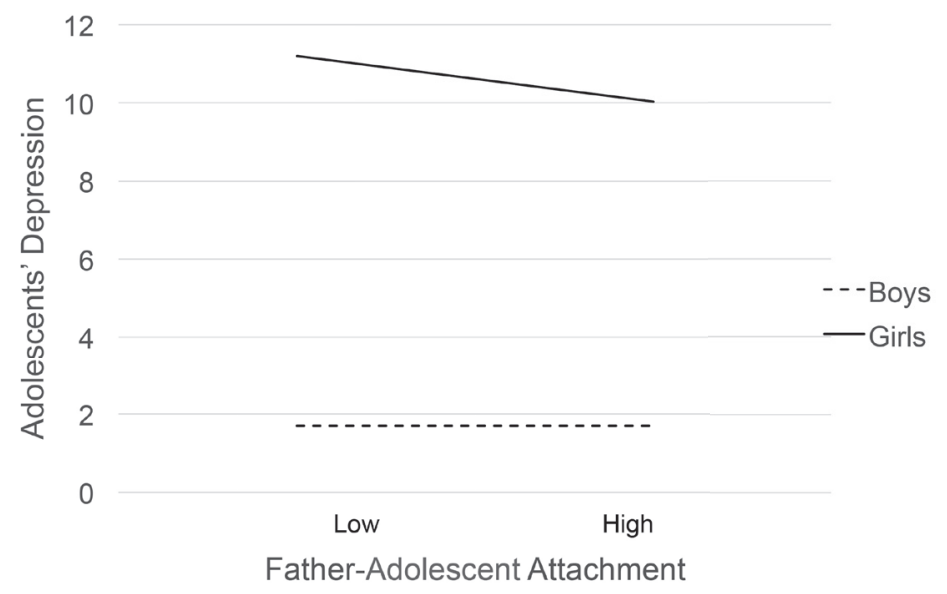

Figure 1. The influence of father-adolescent attachment on adolescents' depression in boys and girls.

Table 4

The Influence of Father-Adolescent Attachment on Adolescents' Anxiety and Moderation Effects of Adolescents' Gender

\begin{tabular}{|c|c|c|c|c|c|c|c|}
\hline & & \multicolumn{2}{|c|}{ Model 1} & \multicolumn{2}{|c|}{ Model 2} & \multicolumn{2}{|c|}{ Model 3} \\
\hline \multicolumn{2}{|r|}{ Variables } & $\beta$ & $t$ & $\beta$ & $t$ & $\beta$ & $t$ \\
\hline \multirow[t]{7}{*}{ Anxiety } & Father-adolescent attachment (A) & -.28 & $-3.78^{* * *}$ & -.22 & $-3.10^{* *}$ & .57 & $2.24^{*}$ \\
\hline & Adolescents' gender (B) & & & .24 & $3.36^{* *}$ & 1.44 & $3.84^{* * *}$ \\
\hline & $A \times B$ & & & & & -1.31 & $-3.25^{* *}$ \\
\hline & $R^{2}$ & \multicolumn{2}{|c|}{.08} & \multicolumn{2}{|c|}{.13} & \multicolumn{2}{|c|}{.18} \\
\hline & $\triangle R^{2}$ & \multicolumn{2}{|c|}{.07} & \multicolumn{2}{|c|}{.12} & \multicolumn{2}{|c|}{.17} \\
\hline & $F$ & \multicolumn{2}{|c|}{14.26} & \multicolumn{2}{|c|}{13.20} & \multicolumn{2}{|c|}{12.80} \\
\hline & $p$ value & \multicolumn{2}{|c|}{.000} & \multicolumn{2}{|c|}{.001} & \multicolumn{2}{|c|}{.002} \\
\hline
\end{tabular}

Note. $N=174$.

${ }^{*} p<.05 .{ }^{* *} p<.01 .{ }^{* * *} p<.001$.

각각에서 애착의 영향을 단순회귀분석으로 알아보았다. 조절 효과의 형태는 Figure 1과 같다. 단순회귀분석에서 남자청소년 에서는 유의한 결과가 나타나지 않았고 $(\beta=-.11, n . s$.$) . 여자청$ 소년에서는 아버지와의 애착이 딸의 우울에 부적으로 유의한 영향을 미치는 것으로 나타났다. ( $\beta=-.42, p<001)$.

다음으로 불안을 종속변인으로 한 위계적 회귀분석 결과가 Table 4에 제시되어 있다. 1단계에서 아버지와의 애착은 우울 과 마찬가지로 청소년의 불안에 부적으로 유의한 영향을 미치 는 것으로 나타났다 $(\beta=-.28, p<.001)$. 이는 애착안정성이 높 을수록 불안이 적은 것을 보여준다. 2 단계에서 청소년의 성 역 시 불안에 미치는 영향이 정적으로 유의한 것으로 나타났다 $(\beta=.24, p<.01)$. 여학생이 남학생보다 불안 수준이 높았다. 마지막으로 3 단계에서 청소년-아버지 애착과 청소년 성 간 의 상호작용이 유의한 것으로 나타났다 $(\beta=-1.31, p<.01)$. 청 소년 성의 조절효과를 설명하기 위해 남자청소년과 여자청소
년 집단 각각에서 애착의 영향을 단순회귀분석으로 알아본 결 과, 여자청소년 집단에서만 애착이 불안에 유의한 영향을 미 치는 것으로 나타났다. 즉 아버지-아들의 애착 관계는 아들의 불안에 유의한 영향을 미치지 않았으나 아버지와의 애착이 딸 의 불안을 유의하게 예측하는 것으로 나타났다 $(\beta=-.38, p<$ .001). 불안에 대한 전체 회귀 모델은 유의하였고 $(F=12.80, p$ <.01) 변량의 약 $18 \%$ 를 설명하는 것으로 나타났다.

Table 4에서 애착과 성의 상호작용이 유의하였으므로 성의 조절효과를 상세히 알아보기 위해 남자청소년과 여자청소년 별로 단순회귀분석을 실시하였고 그 형태는 Figure 2 와 같다. 회귀분석결과 우울과 마찬가지로 불안에 대해서도 아들에 대 한 아버지 애착의 영향은 유의하지 않았으나 $(\beta=-.11, n . s$.$) , 아$ 버지 애착이 딸의 불안에는 부적으로 유의한 영향을 미치는 것으로 나타났다 $(\beta=-.41, p<001)$. 


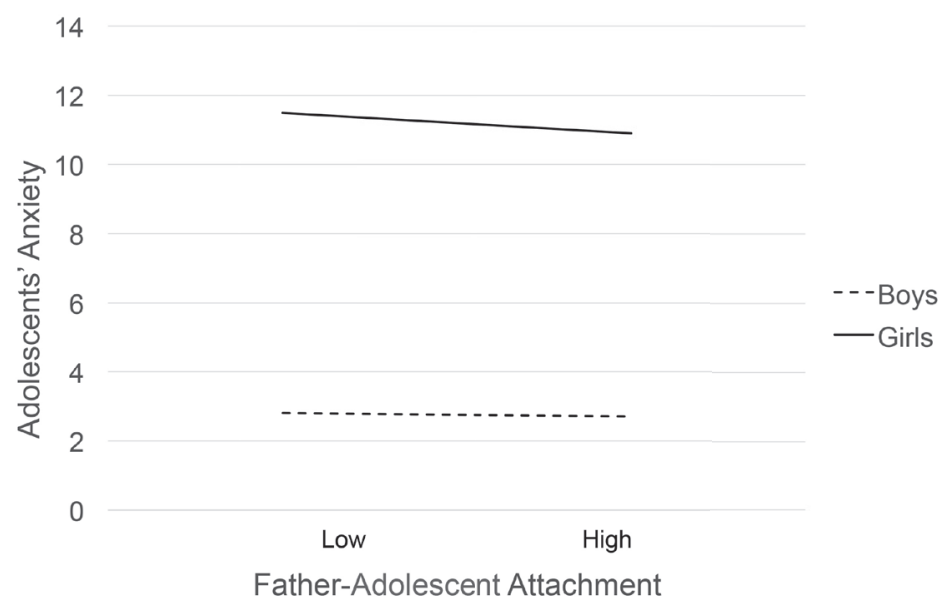

Figure 2. The influence of father-adolescent attachment on adolescents' anxiety in boys and girls.

\section{Discussion}

본 연구에서는 몽골 청소년과 아버지와의 애착관계가 몽골 청 소년의 내현적 문제행동에 미치는 영향을 살펴보았다. 내현적 문제행동 중 우울과 불안에 초점을 맞추었고 몽골 아버지와의 애착의 영향이 청소년의 성에 따라 달라질 것을 가정하고 청 소년 성의 조절효과를 위계적 회귀분석으로 검증하였다. 본 연구에서 나타난 주요한 결과는 다음과 같이 논의될 수 있다.

첫째, 본 연구에서는 몽골남학생이 몽골여학생보다 아버지 와 더 긍정적이고 안정적인 애착관계를 형성한 것으로 나타났 다. 이는 아버지 애착과 아들 사이의 관련성이 딸보다 크다는 Pan 등(2016)의 연구와 유사하다. 특히 이러한 결과에는 몽골 문화에서 아버지가 아들과 직접 상호작용하면서 생활방식을 알려주는 특성이 반영되었을 것으로 생각된다. 아들은 아동기 에서 청소년기를 거쳐 유목과 승마하는 법, 사냥하는 법 등을 배우면서 독립적인 성인으로 성장한다. 딸들도 승마하는 방법 이나 양과 송아지 돌보기 등 유목방법을 배우지만 아버지가 아들에게 기술을 전수하는 경우가 많고 딸들은 어머니를 도와 설거지, 발효제품 만들기 등 가정을 꾸려가는 역할을 많이 한 다(Enkhtuya, 2016).

현대 몽골의 도시화된 사회에서 이러한 전통은 크게 변화 했다. 하지만 자녀들은 어머니보다 아버지를 자신의 롤모델로 서 언급하는 경우가 많았다(Ochir, 2017). 몽골에서는 어머니 가 경제권을 가진 양육자의 역할을 해왔으며 아버지의 존재는 집안의 가장으로서 보다 상징적인 의미를 가진다고 볼 수 있 다. 즉 아버지가 가장으로서 딸보다 아들에게 내재화된 역할 모델이 되는 것이다. 이처럼 딸과 아들이 어머니, 아버지와 관
계를 맺는 방식이 아버지-아들과 아버지-딸 애착 간의 차이에 영향을 주었을 가능성이 있다.

둘째, 본 연구에서는 몽골 청소년과 아버지와의 애착이 청 소년의 내현적 문제행동에 부적으로 영향을 미치는 것으로 나 타났다. 아버지와의 관계를 신뢰롭고 긍정적으로 인식하는 청 소년일수록 우울과 불안이 낮았다. 이러한 결과는 아버지와의 부정적 관계가 몽골 청소년의 높은 불안에 영향을 준다고 보 고한 Tumennast 등(2019)의 연구와 유사하다. 또한 다른 여러 나라의 선행 연구들(Agerup et al., 2015; Grossmann et al., 2002) 을 지지하는 결과이다. 선행 연구들에서 아버지와의 애착안정 성이 높을수록 청소년의 문제행동이 적었으며 아버지와의 불 안정 애착은 심한 수준의 우울 및 부적응과 관련 있는 것으로 보고되었다. 몽골문화에서도 유사한 경향이 나타난 것을 알 수 있다. 특히 본 연구에서는 청소년-아버지 애착이 신뢰, 의 사소통, 소외의 세 가지 영역을 바탕으로 측정되었다. 다시 말 해 청소년이 아버지를 신뢰하며 의사소통을 활발히 하고 있는 지에 따라 정신건강이 영향을 받는다는 것을 보여준다. 이는 몽골청소년과 아버지와의 애착이 청소년들에게 부적응적 상 황과 부적 정서 경험에 대응할 수 있는 정서적인 내적 기반을 제공한다는 것을 시사한다.

마지막으로 본 연구에서 남자청소년과 여자청소년을 나누 어 살펴보았을 때, 청소년-아버지 애착은 남학생에게는 유의 한 영향을 미치지 않았으나 여학생들의 불안과 우울을 부적으 로 유의하게 예측하였다. 즉 아버지와 긍정적인 애착을 형성 한 딸일수록 내현적 문제행동을 적게 보고하였다. 그러나 앞 서 언급한 바와 같이 몽골 사회에서는 아버지와 아들 간의 관 계가 딸과의 관계보다 더 친밀하며 본 연구에서도 아들과 아 
버지와의 애착이 더 높은 것으로 나타났다. 그럼에도 불구하 고 아버지와의 애착은 딸들의 우울과 불안에 유의한 영향을 미쳤다. 이러한 결과는 청소년기에 여자가 남자보다 더 높은 비율의 우울을 보인다는 점을 함께 생각할 필요가 있다. 본 연 구에서는 우울과 불안에서 모두 몽골 여학생이 남학생보다 높게 나타났는데 선행 연구들(Li, DiGiuseppe, \& Froh, 2006; McGuinness et al., 2012)에서도 여자청소년이 내현적 문제행 동에서 더 취약한 것으로 알려졌다. 그러나 아버지와의 관계 가 신뢰롭고 긍정적일수록 딸들의 내현적 문제행동이 감소하 기 때문에, 아버지와의 애착은 여자청소년의 내현적 문제행동 의 중요한 보호요인으로 볼 수 있다.

몽골 문화는 전통적으로 아버지가 아들과 더 가까운 관계 를 형성하긴 하지만, 다른 동양 문화보다 남아선호사상에 영 향을 덜 받는 편이고 유목사회에서 여성이 자율권과 경제적 권한을 가지는 모계 중심적 특성이 있다. 또한 가업을 물려받 는 남성보다 독립적으로 살아가야 할 여성에게 교육의 기회를 더 제공하는 경향도 있다(Burn \& Oidov, 2001; Rossabi, 2021). 이처럼 남성중심의 문화라는 것은 부인할 수 없지만, 여성 도 독자적인 사회적 지위와 자율성을 가지는 경우가 많다. 무 엇보다 현대 사회에서 아버지의 양육 참여가 늘어나는 것으 로 보고되었고 남녀에 상관없이 아버지가 몽골 청소년들에 게 존경받고 자신감을 심어주는 존재로 인식되고 있다(MNB, 2013). 이러한 점이 아버지와의 애착이 보호요인이라는 점을 지지한다. 즉 딸과 아버지와의 애착은 딸들이 자신감 있게 타 인과 의사소통하면서 불안이나 우울을 유능하게 대처할 수 있 는 기제가 될 수 있을 것으로 생각된다. 이후 몽골 청소년의 정 신건강을 위한 교육과 중재에 고려되어야 할 것이다.

한편 본 연구에서 다루지 못한 제한점은 후속연구를 통해 검증할 필요가 있다. 우선, 본 연구에서는 몽골의 청소년과 아 버지와의 애착에 초점을 맞추었으나 어린 시절의 주 양육자인 어머니와의 애착을 함께 고려하지 못한 한계가 있다. 몽골에 서 청소년기에 아버지의 역할이 늘어나는 부분이 어머니 애착 과의 비교를 통해 종단적으로 검증될 필요가 있을 것이다. 다 음으로 본 연구에서는 우울과 불안을 중심으로 내현적 문제 행동을 다루었다. 그러나 위축과 같은 다른 문제행동을 포함 할 필요가 있고 청소년기까지는 아동기와 유사하게 우울증상 이 신체적이고 행동적으로 나타나는 경우가 있으므로 외현적 문제행동과 내현적 문제행동을 함께 고려하는 것이 요구된다. 또한 몽골에서는 문화적으로 정서적 상호작용에 대한 관심이 크지 않았으나 최근에 발생하는 청소년 정신건강 문제로 애착 을 비롯한 부모와의 정서적 관계가 주목받고 있다. 그러나 선
행 연구가 부족하여 몽골부모와 자녀 간의 애착에 대해 명확 한 결론을 내리기 어려운 점이 있다. 따라서 더 포괄적이고 적 극적으로 몽골부모와 청소년 자녀 간의 정서적 상호작용을 연 구할 필요가 있다. 마지막으로 본 연구에서는 초기 청소년기 를 다루었으나 청소년기의 범위가 넓은 만큼 후속 연구에서는 청소년 후기를 포함한 다양한 연령을 다루는 것이 필요하고 부모의 교육수준, 경제적 수준 등 다양한 인구통계학적 특성 을 고려해야 할 것으로 생각된다.

\section{Conflict of Interest}

No potential conflict of interest relevant to this article was reported.

\section{References}

\section{In English}

Achenbach, T. M., \& Rescorla, L. A. (2011). The Achenbach System of Empirically Based Assessment (ASEBA) for ages 1.5 to 18 years. In M. E. Maruish (Ed.), The use of psychological testing for treatment planning and outcomes assessment (3rd ed., Vol. 2, pp. 179-214). London: Taylor \& Franics.

Agerup, T., Lydersen, S., Wallander, J., \& Sund, A. M. (2015). Associations between parental attachment and course of depression between adolescence and young adulthood. Child Psychiatry \& Human Development, 46(4), 632-642. doi:10.1007/s10578-014-0506-y

Baron, R. M., \& Kenny, D. A. (1986). The moderator-mediator variable distinction in social psychological research: Conceptual, strategic, and statistical considerations. Journal of Personality and Social Psychology, 51(6), 1173-1182. doi:10.1037/0022-3514.51.6.1173

Breinholst, S., Esbjørn, B. H., \& Reinholdt-Dunne, M. L. (2015). Effects of attachment and rearing behavior on anxiety in normal developing youth: A mediational study. Personality and Individual Differences, 81, 155-161. doi:10.1016/ j.paid.2014.08.022

Burn, N., \& Oidiv, O. (2001). Women in Mongolia: Mapping progress under transition. New York: United Nations Development Fund for Women.

Chorot, P., Valiente, R. M., Magaz, A. M., Santed, M. A., \& Sandin, B. (2017). Perceived parental child rearing and 
attachment as predictors of anxiety and depressive disorder symptoms in children: The mediational role of attachment. Psychiatry Research, 253, 287-295. doi:10.1016/j.psychres. 2017.04.015

Colin, V. L. (1996). Human attachment. New York: The McgrawHill Companies.

Cooper, M. L., Shaver, P. R., \& Collins, N. L. (1998). Attachment styles, emotion regulation, and adjustment in adolescence. Journal of Personality and Social Psychology, 74(5), 13801397. doi:10.1037/0022-3514.74.5.1380

Duchesne, S., \& Ratelle, C. F. (2014). Attachment security to mothers and fathers and the developmental trajectories of depressive symptoms in adolescence: Which parent for which trajectory? Journal of Youth Adolescence, 43, 641-654. doi:10.1007/s10964-013-0029-z

Freeman, H., Newland, L. A., \& Coyl, D. D. (2010). New directions in father attachment. Early Child Development and Care, 180(1-2), 1-8. doi:10.1080/03004430903414646

Greenberg, M. T. (1999). Attachment and psychopathology in childhood. In J. Cassidy \& P. R. Shaver (Eds.), Handbook of attachment: Theory, research, and clinical applications (pp. 469-496). New York: The Guilford Press.

Grossmann, K., Grossmann, K. E., Fremmer-Bombik, E., Kindler, H., Scheuerer-Englisch, H. S., \& Zimmermann, P. (2002). The uniqueness of the child-father attachment relationship: Fathers' sensitive and challenging play as a pivotal variable in a 16-year longitudinal study. Social Development, 11(3), 307-331. doi:10.1111/1467-9507.00202

Kamkar, K., Doyle, A. B., \& Markiewicz, D. (2012). Insecure attachment to parents and depressive symptoms in early adolescence: Mediating roles of attributions and selfesteem. International Journal of Psychological Studies, 4(2), 3-18. doi:10.5539/ijps.v4n2p3

Lamb, M. E., \& Lewis, C. (2013). Father-child relationships. In N. J. Cabrera \& C. S. Tamis-LeMonda (Eds.), Handbook of father involvement: Multidisciplinary perspectives (2nd ed., pp. 119-134). New York: Routledge.

Lei, L., \& Wu, Y. (2007). Adolescents' paternal attachment and internet use. CyberPsychology \& Behavior, 10(5), 633-639. doi:10.1089/cpb.2007.9976

Li, C. E., DiGiuseppe, R., \& Froh, J. (2006). The roles of sex, gender, and coping in adolescent depression. Adolescence, 41(163), 409-415.

Lieberman, M., Doyle, A. B., \& Markiewicz, D. (1999). Developmental patterns in security of attachment to mother and father in late childhood and early adolescents: Associations with peer relations. Child Development, 70(1), 202-213. doi:10.1111/1467-8624.00015

McGuinness, T. M., Dyer, J. G., \& Wade, E. H. (2012). Gender differences in adolescent depression. Journal of Psychosocial
Nursing and Mental Health Services, 50(12), 17-20. doi:10.3928/02793695-20121107-04

Pan, Y., Zhang, D., Liu, Y., Ran, G., \& Teng, Z. (2016). Different effects of paternal and maternal attachment on psychological health among Chinese secondary school students. Journal of Child Family Studies, 25, 2998-3008. doi:10.1007/s10826-016-0463-0

Rawatlal, N., Kliewer, W., \& Pillay, B. J. (2015). Adolescent attachment, family functioning and depressive symptoms. South African Journal of Psychiatry, 21(3), 80-85. doi:10.7196/SAJP.8252

Rice, F. P., \& Dolgin, K. G. (2005). The adolescent: Development, relationships and culture (11th ed.). Boston, MA: Allyn and Bacon.

Robinson, C. D., Tomek, S., \& Schumacker, R. E. (2013). Tests of moderation effects: Difference in simple slopes versus the interaction term. Multiple Linear Regression Viewpoints, 39(1), 16-24.

Rossabi, M. (2021). Women in modern Mongolia. Asia Society. Retrieved May 31, 2021, from https://asiasociety.org/ education/women-modern-mongolia

Thapar A., Collishaw S., Pine D. S., \& Thapar, A. K., (2012). Depression in adolescence. The Lancet, 379, 1056-1067. doi:10.1016/S0140-6736(11)60871-4

Wilkinson, R. B., \& Goh, D. Y. L. (2014). Structural, age, and sex differences for a short form of the inventory of parent and peer attachment: The IPPA-45. Journal of Relationships Research, 5(e5), 1-11. doi:10.1017/jrr.2014.5

\section{In Korean}

Jung, H. S. (2008). Monggorui yeoseongjeongchaekgwa gwaje [몽 골의 여성정책과 과제]. Gender Review, 8, 75-78.

Kang, H. (2013). The effect of cumulative risk of adolescents on their depression and anxiety. Korean Journal of Youth Studies, 20(9), 175-197.

\section{In Others}

Enkhtuya, B. (2016, February 5). Mongolchuudiin huuhdee humuujuuldeg ulamjlalt arga [Монголчуудын хүҮхдээ хүмҮҮжүҮлдэг уламжлалт арга]. Breaking news. http://www.breakingnews.mn/c/r/22363

Khulan, A., \& Nominerdene, T. (2018, June 28). Setgetsiin emgegtei huuhduudiin ihenh ni tsahim dontoltond urtsun baina [Сэтгэцийн эмгэгтэй ХүҮХдҮҮдийн ихэнх нь цахим донтолтод өртсөн байна]. Itoim. http://itoim.mn/ article/i3uBL/13460/

Mongolian National Broadcaster. (2013. August 21). Huuhdiin 
humuujild nuluuluh aabiin oroltsoo [Television broadcast; ХҮҮхдийн хүмүҮжилд нөлөөлөх аавын оролцоо]. Ulaanbaatar: Mongolian National Broadcaster.

Ochir, T. (2017, May 29). Huuhduudiin 70 orchim hubi ni aaw shigee hun bolohiig husdeg [ХУУХдҮҮдийн 70 орчим хувь нь аав шигээ хүн болохыг хүсдэг]. Zuv Mn. https://zuv.mn/n/9li/

Oyun-Erdene, T., Ichinkhorloo, Sh., Jagalsikhan, O., \& Bulganzaya, T. (2018, February 12). Tanii ugend ordog baih ni 1 huuhed sain humujij buin uzuulelt mun uu? [Таны Үгэнд ордог байх нь л хүҮхэд сайн хүмҮҮжиж буйн ҮзУҮлэлт мөн YY?]. Ikon. https://ikon.mn/n/17y3

Tumennast, G., Bumdari, D., Batbaatar, M., \& Erkhes, A. (2019). Huubdiin humuujil tulubshil humuujild surug nuluu uzuuleh huchin zuil [ХУУхдийн хУмҮУжил төлөвшил, ХүмҮҮжилд сөрөг нөлөө ҮЗУҮлэх хүчин зҮйл]. Ulaanbaatar Family Child Youth Center. https:// mongolmedleg.org/books1/khuuhdiin-khogjil-tolovshil/
Unurmaa, B. (2017, September 19). Usvur nasniihand setgel zuin surgalt yawuulah ni amia horlohoos sergiileh hamgiin zuv arga [Өсвөр насныханд сэтгэлзҮйн сургалт явуулах нь амиа хорлохоос сэргийлэх хамгийн зөв арга]. Ikon. https://ikon.mn/n/13wy

\section{ORCID}

Naranbulag Buyadaa

http://orcid.org/0000-0001-6484-1990

Hana Song

http://orcid.org/0000-0002-7745-7303

Received May 18, 2021

Revision received June 11, 2021

Accepted June 17, 2021 